\title{
Insights into the role of Moringa oleifera in ameliorating acetaminophen induced hepatotoxicity in Nile tilapia, Oreochromis niloticus
}

\author{
L. P. Rema*1 and C. B. Liji ${ }^{2}$ \\ Post Graduate and Research Department of Zoology, \\ Maharaja's College, Ernakulam, Kerala, India.
}

Citation: Rema, L.P. and Liji, C. B. 2021. Insights into the role of Moringa oleifera in ameliorating acetaminophen induced hepatotoxicity in Nile tilapia, Oreochromis niloticus. J. Vet. Anim. Sci. 52(4):399-404

DOI: https://doi.org/10.51966/jvas.2021.52.4.399-404

Received: 27.03.2021

Accepted: 10.09.2021

Published: 15.12.2021

\begin{abstract}
The study was aimed to investigate the hepato-protective effect of Moringa oleifera in Nile tilapia (Oreochromis niloticus) exposed to acetaminophen. Fishes exposed to sub-lethal concentration of acetaminophen for 96 hours, were fed on feed incorporated with moringa leaf, for 21 days. Histological studies of liver of fish fed with M. oleifera leaf incorporated feed, for 21 days after 96-hour acetaminophen exposure showed significant reparative changes when compared to the control. The experiment indicate that dietary supplementation of moringa leaf had hepatoprotective effect in Nile tilapia exposed to acetaminophen.
\end{abstract}

Keywords: Acetaminophen, Moringa oleifera, histopathology, hepatoprotection

Running title: Role of Moringa oleifera in ameliorating acetaminophen induced hepatotoxicity

The presence of pharmaceuticals and active pharmaceutical ingredients (APIs) in the environment have become an emerging problem in recent decades (Heberer, 2002). Acetaminophen ( $\mathrm{N}$-acetyl-para-aminophenol, paracetamol, APAP) is one of the most widely used over-the-counter analgesic and antipyretic agent. Although acetaminophen has a good safety profile at therapeutic levels, it can cause severe hepatic and renal damage when administered in high dose in both in experimental animals and in humans (Agrawal and Khazaeni, 2020; Ghosh and Sil, 2007). Liver being the major organ involved in detoxification shows alterations in response to exposure to harmful components. Conventional hepatoprotective drugs used for the treatment of such adverse reactions are often inadequate. Traditional herbal drugs are significant repositories of chemical constituents which are hepatoprotective in nature. There is an increasing demand for phyto-drugs and therefore it is essential to explore new medicinal plants to ameliorate the hepatotoxic effects of acetaminophen.

1. Associate Professor, Post Graduate and Research Department of Zoology, Maharaja's College Ernakulam, Kerala, India.

2. Research Scholar, Post Graduate and Research Department of Zoology, Maharaja's College Ernakulam, Kerala, India.

${ }^{*}$ Corresponding author: remakannampilly@maharajas.ac.in, Ph. 9447423238

Copyright: () 2021 Rema and Liji. This is an open access article distributed under the terms of the Creative Commons Attribution 4.0 International License (http://creativecommons.org/licenses/by/4.0/), which permits unrestricted use, distribution, and reproduction in any medium, provided the original author and source are credited. 
Moringa oleifera, commonly known as drum-stick, is found mostly in Asia, Africa and South America. It is also known as miracle tree due to its medicinal properties. All parts of this tree such as seed, leaf, root, bark, flower etc. have medicinal value. Moringa oleifera is used as an anti-inflammatory, antioxidant, antidiabetic, antiproliferative, anti-ulcer, hypolipidemic and hepatoprotective agent (Almalk and El Rabey, 2015; Saini et al., 2016; El Rabey et al., 2018; Elbakry et al., 2019). The main objective of this study was to examine the ameliorative and hepatoprotective effect of M.oleifera leaves in acetaminophen induced toxicity in Nile tilapia.

\section{Materials and methods}

Moringa oleifera leaves collected locally from Ernakulam district, were washed in clean water and dried under shade for 7 days. Using a mechanical homogenizer the leaves were powdered. The fine powder was stored in a clean and dry container at room temperature. Acetaminophen exposed fishes were fed with feed mixed with drum stick leaf powder, at a rate of $2.5 \mathrm{~g} / \mathrm{day} / \mathrm{kg}$ for 21 days.

The male $O$. niloticus of mean length $15 \pm 1 \mathrm{~cm}$ weighing about $100 \mathrm{~g}$ were collected from fish farm at Maliankara, Ernakulum district in Kerala, India. The fishes were brought to the laboratory and acclimatized for a week $\left(\mathrm{pH} 6.5\right.$, temperature $28^{\circ} \mathrm{C}$, dissolved oxygen $3.73 \mathrm{mg} / \mathrm{L})$.

The entire experiment was divided into two phases. In the first phase, a control group of 15 fishes after acclimatization, was kept in dechlorinated tap water (Group I). Another group of 15 fishes (Group II) were kept in water containing $1 / 5^{\text {th }} L_{50}$ of acetaminophen (0.33 $\mathrm{ml}$ of acetaminophen per litre of water) for $96 \mathrm{~h}$. The xenobiotic level was maintained constant, after renewal of water every day. After four days, 5 fishes each from Group I and II were sacrificed (Rema, 1995), liver dissected and separately pooled. The liver tissue, washed and wiped thoroughly with blotting paper to remove blood and other body fluids, was then fixed in Bouins fluid for $24 \mathrm{~h}$ and processed further to form the wax blocks. Blocks with the tissue were cut into thin section of five micrometer thickness and stained with haematoxylin and eosin. The sections were observed under phase contrast microscope with attached photomicrography (NIKON ECLIPSE 80 i) under $400 \mathrm{X}$ magnification.

During the second phase, the remaining 10 fishes from Group II were again grouped into two and was subjected to feeding study. One group was fed on normal fish feed (proximate composition: protein $30 \%$, fat $5 \%$, fiber $5.5 \%$ and moisture $11.5 \%$ ) and formed the control for the second phase of experiments. The second group was fed with f normal fish feed incorporated with moringa leaf powderfor 21 days. After the period of feeding, liver was carefully dissected out and processed as described earlier.

\section{Results and discussion}

In the present study, liver of control group showed normal arrangement of hepatic parenchyma with centrally placed nucleus and clear cytoplasm. Each hepatocyte had clear spherical nucleus. Hepatocytes were located among sinusoids and arranged as cords (Fig.1A) Generally healthy teleost fish showed normal architecture with a typical parenchymatous appearance without pathological abnormalities (Vicentini et al., 2005; Figueiredo et al., 2007).

Liver of fish exposed to $1 / 5^{\text {th }} L_{50}$ of acetaminophen for $96 \mathrm{~h}$ showed acute congestion (Fig.1-B). In some regions, hepatocytes were hypertrophied with degeneration of cytoplasm . Necrosis of hepatocytes was seen in almost all regions of liver. Distended sinusoidal space with blood is indicative of acute congestion. Blood vessels were also engorged within the pancreatic tissue also. There was vacuolation in the periphery of hepatic parenchyma and extensive congestion with sinusoids severely expanded with blood. Surrounding the sinusoids there was a fatty infiltration. Pancreatic tissues were highly congested and bile duct was hyperplastic. Degeneration of hepatocytes, nuclear pyknosis in most cells and accumulation of metal binding proteins in its nuclei were reported in the liver of cadmium treated $O$. niloticus (Kaoud et al., 2011). Kavitha et al.(2011) reported 

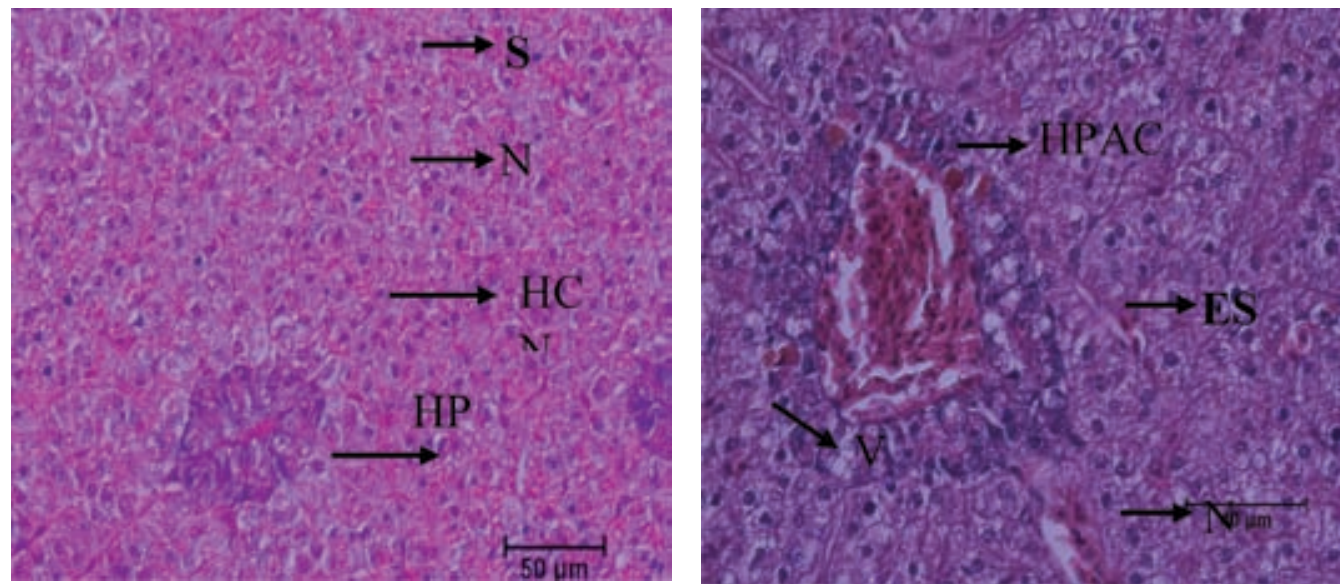

Fig. 1. Histological changes in liver of Nile tilapia in first phase of experiment

A-normal liver (control) showing uniform arrangement of hepatocytes $(\mathrm{HC})$ with normal nucleus $(\mathrm{N})$, normal sinusoids (s) and normal hepatopancreas (HP). B. acetaminophen treated liver $\left(1 / 5^{\text {th }} L^{2} C_{50} 96 \mathrm{~h}\right.$ ) showing acute congestion in hepatopancreas (HPAC), expanded sinusoid (ES), vacuolation (V) and necrosis (N).
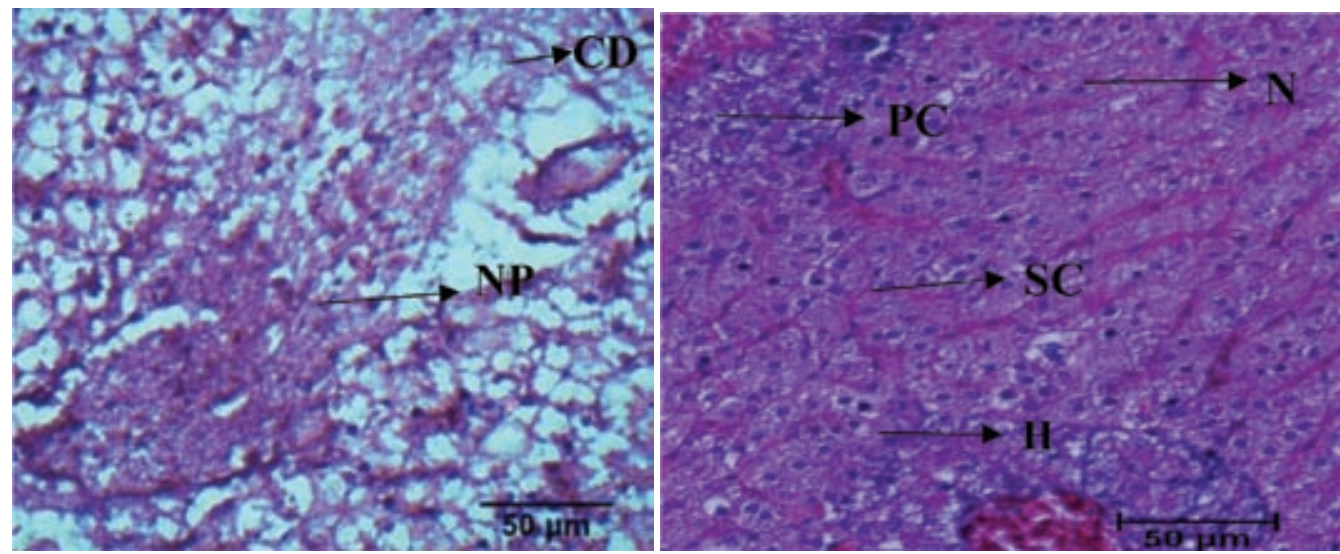

Fig. 2. Histological changes in liver of Nile tilapia in the second phase of experiment

A. Paracetamol treated control liver showed cell death (CD) and nuclear pyknosis (NP). B. Liver of moringa leaves fed group showed comparatively mild sinusoid congestion (SC), pancreatic congestion (PC), normal nucleus $(\mathrm{N})$ and normal hepatocytes $(\mathrm{H})$

hepatocellular vacuolation and blood vessel congestion in $O$. mossambicus exposed to acetaminophen at $500 \mathrm{mg} / \mathrm{Kg}$ orally. Hepatic injuries like degeneration of vacuoles in the cell and necrotic aggregation of cells that was associated with oxidative stress, were observed in Danio rerio exposed to acetaminophen (Jyotsna, 2016).

The liver of control group in the second experiment (acetaminophen treated) showed diffused degenerative changes like extensive pancreatic and hepatocyte congestion. Signs of cell death could be observed with most cells Nuclear pyknosis was a consistently observation. Cytoplasmic architecture was also completely lost compared with the test group. Blood vessels were highly congested and filled with blood. Erythrocyte infiltration into sinusoids was observed. Loss of reticular fibres, which cross links and act as a supporting mesh in soft tissues of liver, was a common feature (Fig. 2. A). Liver is one of the main organs which regulates many important metabolic functions and hepatic injury directly affects metabolic functions of the liver (Mitra et al., 1998).

Histopathological evaluation plays a major role in the assessment of the harmful effects of xenobiotics (Reddy and Rawat, 2013). Van der Oost et al. (2003), reported that histopathological examinations have long 
been recognized to be reliable biomarkers of fish exposed to stress. Hepatotoxicity is one of the very common disorders resulting in serious debilities ranging from severe metabolic disorders to mortality (Patel et al., 2008). Paracetamol is considered as a safe drug, if consumed at correct dose rates. But overdose may lead to dangerous and fatal conditions (Penna and Buchanan, 1991), as this drug is hepatotoxic at high concentrations. The liver is one of the major organs responsible for the metabolism of endogenous and exogenous compounds and one of the first target organs to toxic insults (Cao et al., 2016).

Compared to control group, liver of fish fed with feed containing moringa leaves, showed lesser signs of hepatotoxicity. In moringa leaf treated group, hepatocytes had normal arrangement with prominent nucleus. Hepatic cells maintained their round polygonal shape. The size of the hepatic cells reflects their physiological functional state. In some regions the cells showed mild enlargement, mild nuclear hypertrophy and sinusoids showed minute swelling. Mild pancreatic congestion and mild vacuolation were also observed in some regions (Fig. 2. B). Uma et al. (2010) and Fakurazi et al. (2012) observed that $M$. oleifera leaves were able to protect acetaminophen-induced liver damage by decreasing liver enzymes and hepatic lipid peroxidation as well as by increasing antioxidant enzyme levels. Many plants and their products have the potential to protect liver from toxic effects of hepatotoxins. This is due to the presence of active constituents such as alkaloids, sterols and flavonoids which have free radical scavenging activities (Anwer et al., 2008). In our study also, the tissues of liver of moringa fed fish showed considerable reparative changes. Ross and Kasum (2002) reported, that plant secondary metabolites such as flavonoids have much antioxidative, anti-inflammatory, anti-proliferative, radicalscavenging activity and pro-apoptotic effects in various cell types. Tekle and Sahu (2015) investigated the ameliorative effects of moringa flower on $O$. niloticus subjected to Aeromonas hydrophila induced stress. Moringa leaves have efficient antioxidant properties (He et al., 2018). The beneficial functions of $M$.oleifera are closely associated to its high content of phytochemicals such as flavonoids, glucosinolates, phenolic acids and isothiocyanates (El-Hadary and Ramadan, 2019).

\section{Conclusion}

The present study emphasises the protective role of moringa leaves against acetaminophen induced damages in liver tissue of Nile tilapia. Administration of moringa leaves partially restored the general structure of the liver. Moringa leaves may be considered as a potential source of natural antioxidants and phytochemicals against hepatotoxicity.

\section{Conflict of interest}

The authors declare that they have no conflict of interest.

\section{References}

Agrawal, S. and Khazaeni, B. 2020. Acetaminophen toxicity. Statpearls [internet]. StatPearls Publishing, Treasure Island (FL), pp 1-11.

Al-Malk, A.L. and El Rabey, H. A. 2015. The antidiabetic effect of low doses of Moringa oleifera Lam. seeds on streptozotocin induced diabetes and diabetic nephropathy in male rats. BioMed. Res. Intl. 2015: http:// dx.doi.org/10.1155/2015/381040.

Anwer. M.S., Mohtasheem. M., Azha, I., Ahmed. S.W. and Bano. H. 2008. Chemical constituents from Melilotus officinalis. J. Basic Appl. Sci. 4(2): 89-94.

Cao, L., Du, J., Ding, W., Jia, R., Liu,Y., Xu, P. and Yin, G. 2016. Hepatoprotective and antioxidant effects of dietary Angelica sinensis extract against carbon tetrachloride-induced hepatic injury in Jian Carp (Cyprinus carpio var. Jian). Aqua. Res. 47(6): 1852-1863.

El Rabey, H.A., Khan, J.A., Sakran, M.I. and Al-Ghamdi, M.A. 2018. The antioxidant activity of low doses of Moringa Seeds (Moringa oleifera Lam.) in hypercholesterolemic male rats. ROS. 6(17): 363-370. 
Elbakry, M.A., El Rabey, H.A., Elremaly, W., Sakran, M.I. and Almutairi, F.M.2019.The methanolic extract of Moringa oleifera attenuates $\mathrm{CCl} 4$ induced hepatonephro toxicity in the male rat. Biomed. Res. 30 (1): 23-31.

El Hadary, A.E. and Ramadan, M.F. 2019. Antioxidant traits and protective impact of Moringa oleifera leaf extract against diclofenac sodium-induced liver toxicity in rats. J. Fd. Biochem. 43(2): e12704.

Fakurazi,S.andSharifudin, S.A.2012.Arulselvan P. Moringa oleifera hydroethanolic extracts effectively alleviate acetaminophen-induced hepatotoxicity in experimental rats through their antioxidant nature. Molecules. 17(7): 8334-8350.

Figueiredo-Fernandes, A., Ferreira-Cardoso, J.V., Garcia-Santos, S., Monteiro, S.M., Carrola, J., Matos, P. and FontaínhasFernandes, A. 2007. Histopathological changes in liver and gill epithelium of Nile tilapia, Oreochromis niloticus, exposed to waterborne copper. Pesq. Vet. Bras. 27(3): 103-109.

Ghosh, A. and Sil, P.C. 2007. Anti-oxidative effect of a protein from Cajanus indicus $\mathrm{L}$ against acetaminopheninduced hepato-nephro toxicity. $B M B$ Reports. 40(6): 1039.

He, T. B., Huang, Y. P., Huang, Y., Wang, X. J., Hu, J. M. and Sheng, J. 2018. Structural elucidation and antioxidant activity of an arabinogalactan from the leaves of Moringa oleifera. Int. J. Biol. Macromol. 112: 126-133.

Heberer, T.2002. Occurrence, fate, and removal of pharmaceutical residues in the aquatic environment: a review of recent research data. Toxicol. Lett. 131(1-2): 5-17.

Jyotsna, S.Y. 2016. Effect of flavonoids in acetaminophen induced liver injury in Danio rerio. Int. J. Heal. Sci. Res. 5: 352-359.
Kaoud, H.A., Zaki, M.M., El-Dahshan, A.R, Saeid, S. and El Zorba, H.Y. 2011. Amelioration of toxic effects of cadmiumexposure in Nile tilapia (Oreochromis niloticus) by using Lemna gibba L. Life Sci. J. 8(1): 185-195

Kavitha, P., Ramesh, R., Bupesh, G., Stalin, A. and Subramanian, P. 2011. Hepatoprotective activity of Tribulus terrestris extract against acetaminopheninduced toxicity in a freshwater fish (Oreochromis mossambicus). Invitro Cell. Dev. Biol. Anim. 47(10): 698-706.

Mitra, S.K., Venkataranganna, M.V., Sundaram, R. and Gopumadhavan, S. 1998. Protective effect of HD-03, a herbal formulation, against various hepatotoxic agents in rats. J. Ethnopharmacol.63(3): 181-186.

Patel, R. K., Patel, M. M., Patel, M. P., Kanzaria, N. R., Vaghela, K. R. and Patel, N. J. 2008. Hepatoprotective activity of Moringa oleifera Lam. fruit on isolated rat hepatocytes. Phcog Mag. 4:118-123.

Penna, A. and Buchanan, N. 1991. Paracetamol poisoning in children and hepatotoxicity. B.J.C.P. 32(2):143-149.

Reddy, P.B. and Rawat, S.S. 2013. Assessment of aquatic pollution using histopathology in fish as a protocol. Int. Res. J. Environ. Sci. 2(8): 79-82.

Rema.L.P.1995.Biochemicalresponsestoheavy metals in Oreochromis mossambicus (Peters) with special reference to metal detoxifying mechanisms. Ph.D. thesis. Cochin University of Science and Technology, Cochin.

Ross, J.A and Kasum, C.M. 2002. . Dietary flavonoids: bioavailability, metabolic effects, and safety. Ann. Rev.Nutr. 22(1): 19-34

Saini, R. K., Sivanesan, I. and Keum, Y.S. 2016. Phytochemicals of Moringa oleifera: a review of their nutritional, therapeutic and industrial significance. Biotech.6(2): 203. 
Tekle, E.W. and Sahu, N.P. 2015. Growth and immunodulatory response of Nile tilapia Oreochromis niloticus fingerlings to ethanolic extract of Moringa oleifera flower. I.J.S.R.P. 5(7): 285-296.

Uma, N., Fakurazi, S. and Hairuszah, I. 2010. Moringa oleifera enhances liver antioxidant status via elevation of antioxidant enzymes activity and counteracts paracetamol-induced hepatotoxicity. M.J.N. 16(2): 293-307.
Van der Oost, R., Beyer, J. and Vermeulen, N.P. 2003. Fish bioaccumulation and biomarkers in environmental risk assessment: a review. Environ. Toxicol. Pharmacol .13(2): 57- 149.

Vicentini, C.A, Franceschini-Vicentini, I. B., Bombonato, M.T.S., Bertolucci, B., Lima, S.G. and Santos, A.S. 2005. Morphological study of the liver in the teleost Oreochromis niloticus. Int.J. Morphol. 23(3): 211-216. 